\title{
Research progress on refractory composition and deformability of shell molds for TiAl alloy castings
}

\author{
*Chun-ling Bao', Shuang-qi Zhang ${ }^{2}$, Yu-yan Ren', You-wei Zhang', Hua-sheng Xie' and Jun Zhao' \\ 1. Titanium Alloy Division, Shenyang Research Institute of Foundry, Shenyang 110022, China \\ 2. School of Materials Science and Engineering, Shenyang University of Technology, Shenyang 110870, China
}

\begin{abstract}
At present, most TiAl components are produced by an investment casting process. Environmental and economic pressures have, however, resulted in a need for the industry to improve the current casting quality, reduce manufacturing costs and explore new markets for the process. Currently, the main problems for investment casting of TiAl alloys are cracks, porosities, and surface defects. To solve these problems, many studies have been conducted around the world, and it is found that casting defects can be reduced by improving composition and properties of the shell molds. It is important to make a summary for the related research progress for quality improvement of TiAl castings. So, the development on refractory composition of shell molds for TiAl alloy investment castings was reviewed, and research progress on deformability of shell mold for TiAl alloy castings both at home and abroad in recent years was introduced. The existing methods for deformability characterization and methods for improving the deformability of shell molds were summarized and discussed. The updated advancement in numerical simulation of TiAl alloy investment casting was presented, showing the necessity for considering the deformability of shell mold during simulation. Finally, possible research points for future studies on deformability of shell mold for TiAl alloy investment casting were proposed.
\end{abstract}

Key words: TiAl based alloys; investment casting; shell mold; deformability

CLC numbers: TG146.23 Document code: A Article ID: 1672-6421(2018)01-001-10

$\mathrm{N}$ ickel based superalloys are currently widely used as high temperature structural materials. However, it is more and more difficult to increase the service temperature because of the inherent limitation of superalloys. Due to the co-existence of metallic and covalent bond, intermetallic materials have higher specific strength and rigidity than common metals and better ductility than ceramics, which can be a potential substitute for conventional superalloys. Among these, TiAl based alloys are becoming competitive materials for heat-resistant structural components in aero and auto engines and have great application potential for their low density, at only half of nickel based alloys, as well as good creep resistance and oxidation resistance ${ }^{[1]}$. In 2007, the US Boeing company declared that TiAl alloys would be used for low pressure turbine blades in GEnx engine on the 787 airplane, which could reduce the weight of the engine by 800 pounds ${ }^{[2]}$. That was a milestone for the application of TiAl alloys to reduce

\section{* Chun-ling Bao}

Female, born in 1980, Ph.D candidate, senior engineer. Her research interests mainly focus on casting technologies of titanium alloys. To date, she has published more than 30 papers.

E-mail: baochunling0323@126.com

Received: 2017-06-27; Accepted: 2017-12-25 engine weight and prompt the application of TiAl alloys around the world. In recent years, the studies on TiAl alloys were focused on the relationship among process, microstructure and mechanical properties, manufacturing and forming technologies, as well as the TiAl based composite materials ${ }^{[3-7]}$. Until now, processes similar to those for nickel based alloys have been developed for manufacturing and forming of TiAl alloys, including ingot metallurgical methods (casting ingot plus thermal mechanical treatment), casting process and powder metallurgy.

Casting methods such as investment casting process ${ }^{[8]}$, permanent mold casting process ${ }^{[9]}$ and centrifugal casting process ${ }^{[10]}$ are still the main forming technology for TiAl components for their low cost and net shape advantages over other forming technologies. Among which, the investment casting method is usually used to form parts for aero and auto engine blades and high pressure turbine blade shield plates due to the accurate casting dimensions and high surface quality.

Although the investment casting process of TiAl alloys has the advantages of net shape and low cost, problems including cracks, porosities and surface defects are easily found in castings ${ }^{[11,12]}$. The investment casting process consists of several steps in which one of the key steps is production of a ceramic shell since 
soundness and quality of the ceramic shell has a direct effect on the soundness of the castings ${ }^{[13]}$. The residual stress and subsequent distortion in castings can be related to the difference between the thermal expansion characteristics of the alloy and the ceramic shell ${ }^{[13]}$. Mechanical interaction between the ceramic shell mold and solidifying alloy can cause residual stress, distortion and hot tearing cracks. According to statistics, more than $70 \%$ of defects and scraps of TiAl alloy castings are caused by shell mold quality, so the property of the shell mold is an important issue for TiAl alloy precision casting ${ }^{[14]}$. To solve these problems, a lot of studies have been carried out on shell molds for TiAl alloy castings in the aspect of composition and deformability of the shell molds ${ }^{[15-19]}$.

Different shell making processes and refractory materials can be tried to improve the deformability of shell mold to match the shrinkage of the TiAl alloy during solidification, reduce the stress caused by shrinkage difference and finally increase the casting quality. In this paper, the development and research progress on refractory materials of shell molds for TiAl alloy investment castings are reviewed, the study on deformability of shell molds is summarized and finally the key points for future study on shell mold deformability are proposed.

\section{Research and development progress on refractory composition of shell molds for TiAl alloy investment castings}

Considering the characteristic of TiAl alloys such as high brittle ductile transition temperature, narrow solidification range, reactivity of melt with mold materials ${ }^{[20]}$, most TiAl parts, especially complex components, are produced by the investment casting process for its advantage over other casting processes and forming technologies. Environmental and economic pressures have, however, resulted in a need for the industry to reduce the rate of rejects and material consumption by improving current casting quality, and reduce manufacturing costs. Optimization of the mechanical and physical properties of the ceramic shell mold will be fundamental to achieve these aims ${ }^{[21]}$. The shell mold should possess properties such as sufficient green or unfired strength to withstand the pressure during pattern removal, proper fired strength to resist the weight of the hot molten alloy, and a certain deformability to reduce crack defects in castings caused by residual stress, high resistivity to chemical reaction to inhibit alloy-shell reaction, good collapsibility to remove the casting without damage, good permeability to allow the hot gases inside the melt to release easily and reduce the porosity defects in castings ${ }^{[14]}$.

As TiAl alloy melt has a high chemical reactivity and can react with almost all refractory materials, which could cause deteriorated inner and surface quality of the investment castings, the selection of refractory materials for the shell mold surface becomes a key issue for the development of ceramic shell molds ${ }^{[15]}$. The graphite shell mold which is normally used for titanium alloy castings were firstly tried for the TiAl alloy. The research found that rapid exothermic reactions could occur when the graphite shell mold contacted with the melted TiAl alloys, especially for castings needing high preheat temperature of the shell mold, and also found the large shrink ratio of the graphite shell reduces the accuracy of the castings. For solving the problems for the graphite shell mold, new materials available were studied. The US Rem company developed a ceramic shell to replace the graphite shell mold, which was called tungsten surface layered ceramic shell mold. Castings can get good surface accuracy and less roughness due to the high strength, small contraction and low surface adhesiveness of the tungsten surface layered ceramic shell mold, which is suitable for small sized titanium alloy castings with complex inner shape. However, the high thermal conductivity of the metal surface layer could easily cause cold shut defect in castings and the cost of the molding materials was also high ${ }^{[5]}$.

Several kinds of ceramic shell molds were developed for TiAl based alloy investment castings. Among those, the oxide ceramic shell mold becomes a very promising one to replace the graphite and tungsten surface layered ceramic shell mold ${ }^{[6]}$. The first selection of $\mathrm{SiO}_{2}$ as the refractory material was failed for application because of the strong reaction with titanium alloy, making $\mathrm{Ti}$ to be $\mathrm{TiO}_{2}$. Wictorin et al ${ }^{[15]}$ studied the possibility of a $\mathrm{MgO}$ shell mold and found $\mathrm{Mg}$ was easily volatilized at $1,600{ }^{\circ} \mathrm{C}$ under vacuum condition which caused obvious porosity in the castings. Later on, $\mathrm{CaO}$ and $\mathrm{ZrO}_{2}$ were used as refractory materials ${ }^{[17]}$. It was found that a strict control for moisture was needed for the $\mathrm{CaO}$ type shell mold because cracks can easily occur due to its spontaneous hydration feature; severe chemical reaction occurred between $\mathrm{ZrO}_{2}$ and TiAl alloy melt since many impurities were found when melting TiAl alloys using a $\mathrm{ZrO}_{2}$ ceramic crucible.

With the increased accuracy demand for TiAl alloy castings, $\mathrm{Y}_{2} \mathrm{O}_{3}$ is gradually becoming the study objectives because of the good casting surface quality. While, considering the high cost of $\mathrm{Y}_{2} \mathrm{O}_{3}$, a mixture of rare earth oxides were also chosen as refractory materials to improve the surface quality of TiAl alloy castings and at the same time decrease the cost. Some studies also considered using $\mathrm{CaZrO}_{3}$ as the surface layer material for TiAl alloy casting shell mold to improve casting quality. Kim et al. ${ }^{[23]}$ studied the application of $\mathrm{CaZrO}_{3}$ based face coat materials. The results showed that the $\mathrm{CaZrO}_{3}$ face coat had comparable chemical inertness to $\mathrm{ZrO}_{2}$, at a lower cost than yttria based systems. Later, $\mathrm{Li}^{[24]}$ developed a $\mathrm{CaZrO}_{3}$ crucible by sintering $\mathrm{ZrO}_{2}$ and $\mathrm{CaO}$ powders. In 2012, a study was proposed to use $\mathrm{CaZrO}_{3}$ as filler material in the face coat ${ }^{[25]}$. In recent years, $\mathrm{Al}_{2} \mathrm{O}_{3}$ became the new study interest for shell molds. Similar thermal expansion coefficient of $\mathrm{Al}_{2} \mathrm{O}_{3}$ to $\gamma$-TiAl is positive for investment casting of TiAl alloys. Although the high aluminium content of TiAl based alloys may help to lower their reactivity in the molten state, only a few investigations have been concerned with casting TiAl alloys using $\mathrm{A} 1_{2} \mathrm{O}_{3}$ crucibles or shell moulds. Kuang et al. ${ }^{[26]}$ showed that a TiAl alloy melted in an $\mathrm{Al}_{2} \mathrm{O}_{3}$ crucible contained a few inclusions and there was evidence of cracks near the interaction region. 
The chemical reaction was considered to be a more serious problem. According to Wang et al. ${ }^{[27]}$, there was a reaction layer as thick as $200 \mu \mathrm{m}$ and a hardened zone about $500 \mu \mathrm{m}$ thick on the surface of cast TiAl material when an alunima shell mould was used. However the recent research of Kim et al ${ }^{[28]}$ showed that interface reaction between $\mathrm{Al}_{2} \mathrm{O}_{3}$ and TiAl alloy melt can be significantly reduced with a suitable binder, which is favorable for TiAl alloy castings and implied future potential application of $\mathrm{A}_{2} \mathrm{O}_{3}$.

\section{Deformability of shell mold for TiAl investment casting}

\subsection{Characterization and testing methods of deformability for shell mold}

There is still no standard method for the deformability measurement of shell molds. Some researchers use stress level induced in castings to assess deformability of molds. However, the measurement of casting internal stress is difficult and expensive, so the method is not suitable for practical control of casting quality.

Normally, bending strength both at ambient temperature and high temperatures are used for deformability characterization. Both three-point and four-point bending tests can be used, as shown in Fig. 1. For the three-point bending test, the shell molds are cut into rectangular test bars and the bending strength is calculated using Eq. (1) ${ }^{[18]}$ :

$$
\sigma_{f}=\frac{3 P L}{2 b d^{2}}
$$

where $P$ is the load at breaking point, $L$ is the span between two supports, $b$ is the sample width and $d$ is the sample height.

The most frequent site of mold failure during dewaxing and casting is at the sharp radii and corners, but the bending test cannot determine the ability of the mold to resist cracking in these areas. Thus, a wedge test was then developed by Leyland et al. ${ }^{[13]}$ to evaluate the strength and load capacity at edges and corners of shell molds, as shown in Fig. 2. The adjusted fracture load of the wedge sample $\left(\mathrm{AFL}_{w}\right)$, defined as the load needed to break a $10-\mathrm{mm}$ wide wedge test piece with a $20-\mathrm{mm}$ span length, normalizes the load bearing capacity of the shell mold at edges and can be expressed as Eq. (2):

$$
\mathrm{AFL}_{w}=f_{w} \sigma_{\text {edge }} T^{2}
$$

where $\mathrm{AFL}_{w}$ is the adjusted fracture load of the wedge sample, $f_{w}$ is a constant equal to $0.17, \sigma_{\text {edge }}$ is the strength of the edge.

Some researchers proposed to use high temperature compressive strength and elastic modulus to assess the deformability of molds. The problem is that the high temperature elastic modulus is not easily measured because of small deformation during compression tests ${ }^{[29]}$.

At present, the I-shaped specimen for TiAl castings, as shown in Fig. 3, is frequently used for the deformability assessment of a TiAl alloy casting shell mold by counting the cracks in the casting specimen. The greatest advantage of this method is that it can directly relate the deformability of shell molds to crack
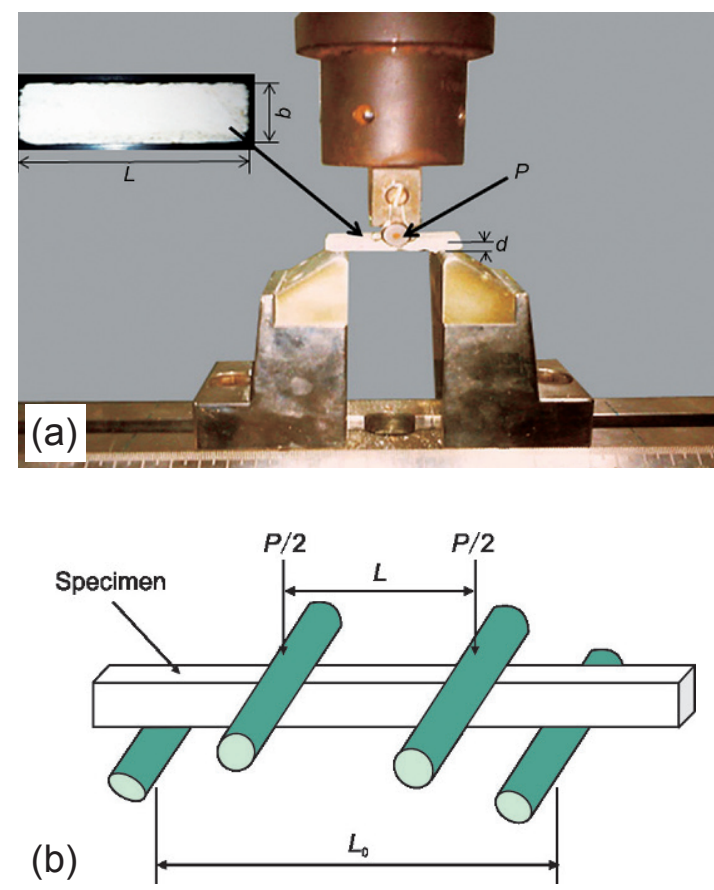

Fig. 1: Schematic for shell mold bending tests: (a) threepoint bending test ${ }^{[18]}$, (b) four-point bending test ${ }^{[29]}$

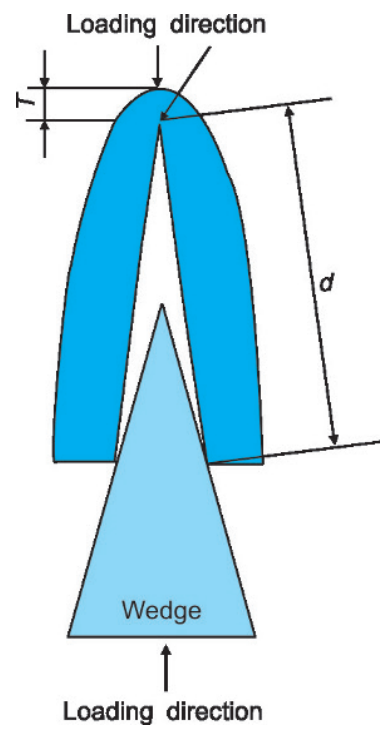

Fig. 2: Schematic loading configuration for wedge test ${ }^{[13]}$

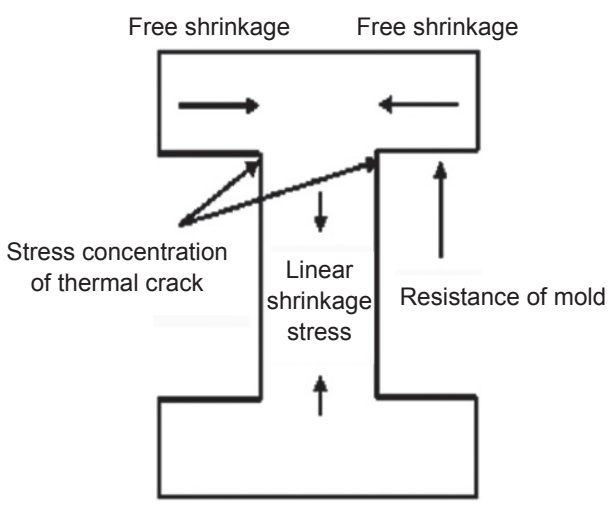

Fig. 3: Schematic drawing for stress analysis and crack counting of I-shaped TiAl casting ${ }^{[20]}$ 
formation of castings. The drawback is that the method cannot give a quantitative characterization of the deformability index of shell molds.

\subsection{Research progress in China}

During the past 20 years, China domestic institutes and scholars have carried out many studies on microstructure, deformation property, alloying and manufacturing technologies of TiAl alloys. Several studies also have been done on deformability of shell molds for TiAl alloy castings. Chen et al. ${ }^{[30]}$ found that particle size distributions (PSDs) of zirconia powders play an important role in determining the quality of zirconia ceramic molds and thus on the quality of TiAl components produced by the investment casting process. Three $\mathrm{CaO}$ stabilized zirconia powders with different PSDs were used in the study: CSZ1, CSZ2 and CSZ3 with the median particle diameters of 20, 30 and $40 \mu \mathrm{m}$ respectively. The PSDs of the zirconia powders were shown in Fig. 4. The sand CSZ3 had a broader PSD while the sand CSZ1 presented a narrow PSD among the three zirconia powders. The sand CSZ2 contained mixed powder sizes and had a moderate PSD. As seen from the data presented in Fig. 5, the bend strength of zirconia ceramic molds was affected by two factors, namely, particle size and PSDs. The CSZ2 with a moderate PSD had the

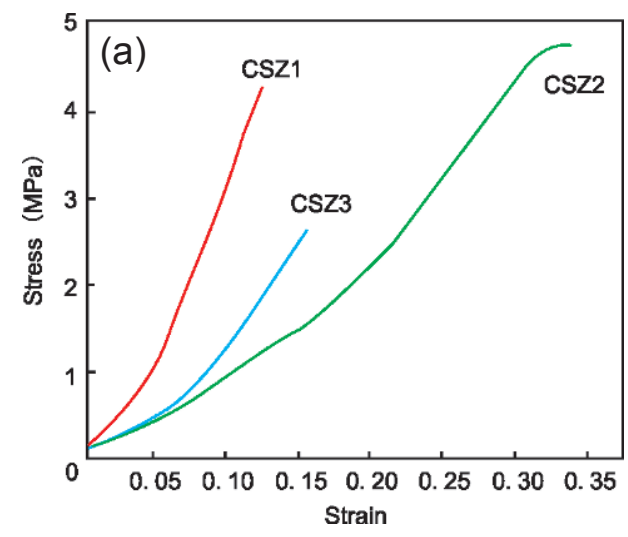

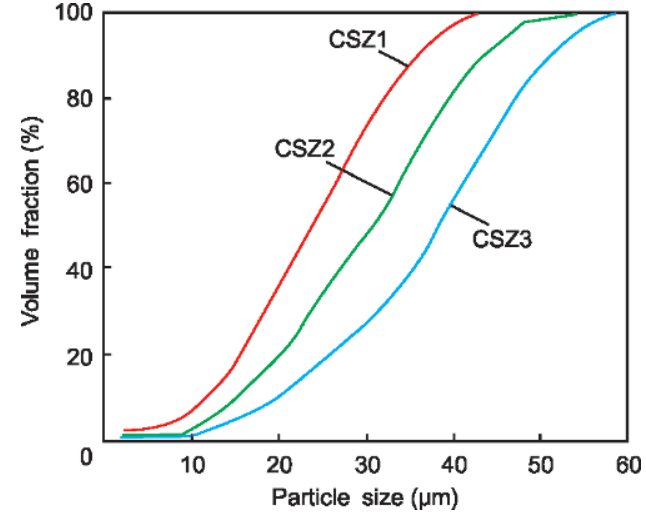

Fig. 4: Particle size distributions of zirconia powders ${ }^{[26]}$

highest strength. Although CSZ1 had the highest specific surface area (smaller particle size) than others, its bend strength was lower than that of the CSZ2. This most probably resulted from the higher porosity associated with lower stacking density of CSZ1. It was recommended that the mechanical properties of zirconia ceramic molds can be attributed to the contact surface and residual porosity within the ceramic body ${ }^{[30]}$. Therefore, it is possible to improve the deformability of a ceramic shell mold by selecting certain PSDs.

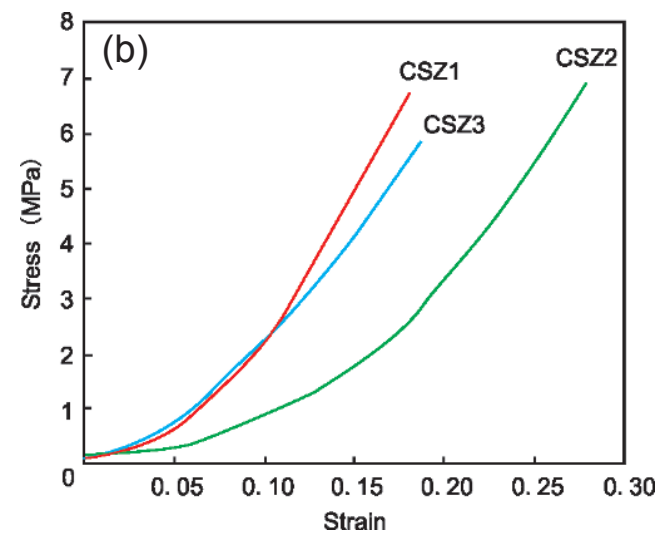

Fig. 5: Stress-strain curves of zirconia mold prepared with different PSDs: (a) green, (b) fired ${ }^{[26]}$

The research of Li et al. ${ }^{[31]}$ found that the deformability and air permeability of a shell mold can be effectively increased by adding a small amount of carbon fibers and dextrines. In 2013, Zhou in AVIC Shenyang Engine Design Institute studied the deformability by adding high polymers and water emulsions in the back layer of shell mold ${ }^{[16]}$. Porosities can be found in the shell molds after baking with certain amount additions of high polymers and water emulsions, which reduced the shell strength and caused increased deformability of the shell mold. Meanwhile, the porosities reduced the heat transfer between the shell mold and castings, which will also reduce the contraction stress of the castings. The results showed that the optimal amount of polymers + water emulsions addition is $0.02 \%-0.03 \%$, when the highest qualified rate of TiAl thin walled castings can be achieved by an obvious reduction of the crack defects, which can be attributed to increased shell deformability and reduced heat transfer between the shell mold and castings by the introduction of porosities in shell molds. Zhao from Harbin
Institute of Technology studied the deformability of the ceramic shell mold by adding nylon fibers, carbon fibers and glass fibers in the coating materials ${ }^{[20]}$. Shell molds with different fibers additions were prepared and I-shaped TiAl specimens were cast, as shown in Fig. 6. The comparison of cracks in different specimen castings indicated that shell molds with nylon fibers had better deformability and could reduce the crack rate.

Sun et al. studied the deformability of TiAl casting shell mold by using silica sol, ethyl silicate and alternating with silica sol and ethyl silicate as the back layer binders ${ }^{[32]}$. The research showed that the bending strength of shell molds using silica sol and ethyl silicate alternatively as the back layer binders could be reduced compared with the shell molds using silica sol or ethyl silicate individually as the back layer binder. The deformability of the shell mold using silica sol and ethyl silicate alternately as the back layer binders can be verified to be improved accordingly by comparing the I-shaped specimen castings with different shell molds, as shown in Fig. 7. 


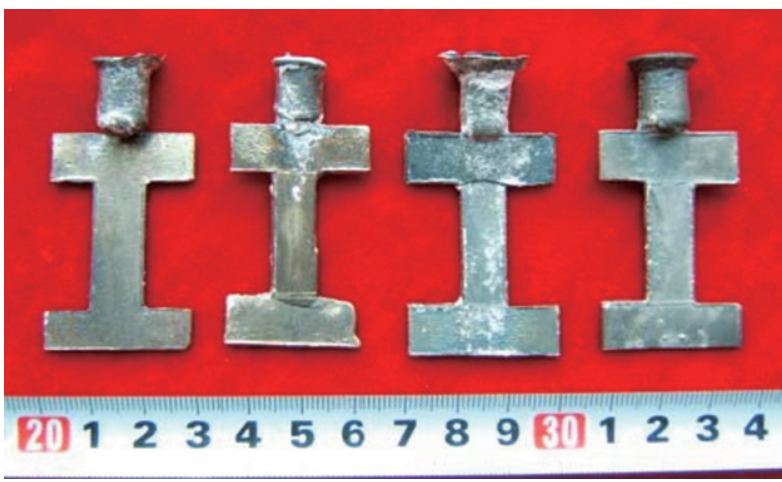

Fig. 6: Ti-47.5Al-2.5V-1Cr l-shaped specimen castings with different fibers addition in shell mold: (a) glass fibers; (b) carbon fibers; (c) without fiber addition; (d) nylon fibers ${ }^{[20]}$
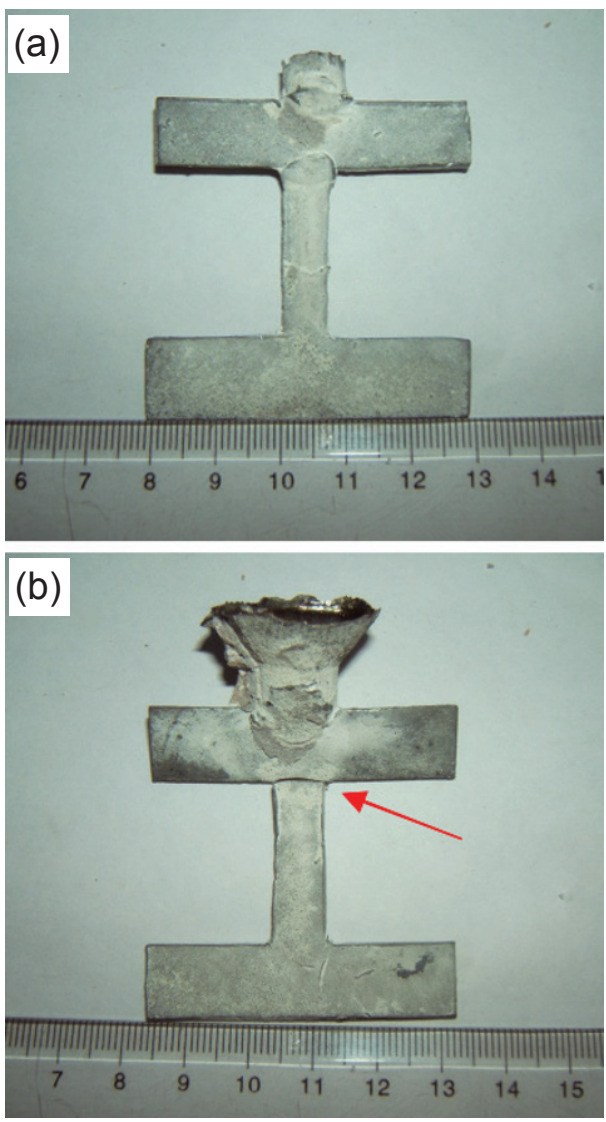

Fig. 7: I-shaped specimen castings using shell molds with different back layer binders: (a) with alternate binders; (b) with silica sol binder ${ }^{[32]}$

Chen et al. studied the deformability improvement of $\mathrm{ZrO}_{2}$ type ceramic shell mold for TiAl investment casting ${ }^{[18]}$. High polymers were also added in the ceramic shell mold and the influence was systemically studied. The stress-strain curves before and after baking of the shell molds with different contents of high polymers were compared, as shown in Fig. 8 and Fig. 9. It could be seen that the strength of the shell molds with high polymers addition increased before baking and decreased after baking, which caused improvement of shell deformability. This method of adding high polymers in the shell mold to improve deformability can also be helpful for reducing the sand cleaning work on TiAl castings because of reduced surface cracks of the shell mold.

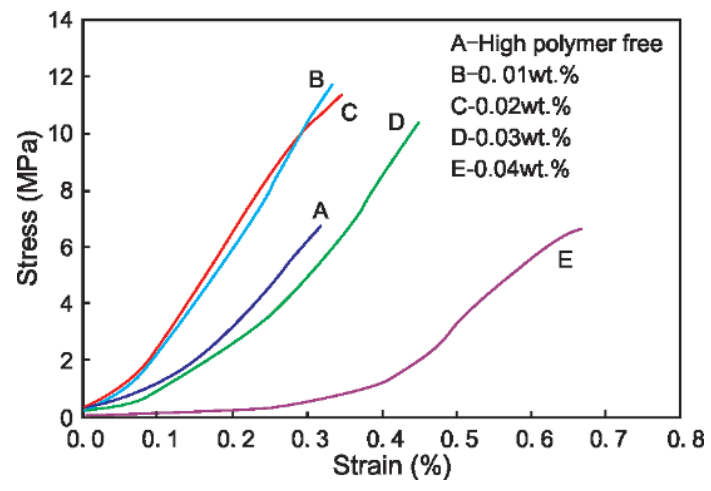

Fig. 8: Stress-strain curves of different shell molds before baking ${ }^{[18]}$

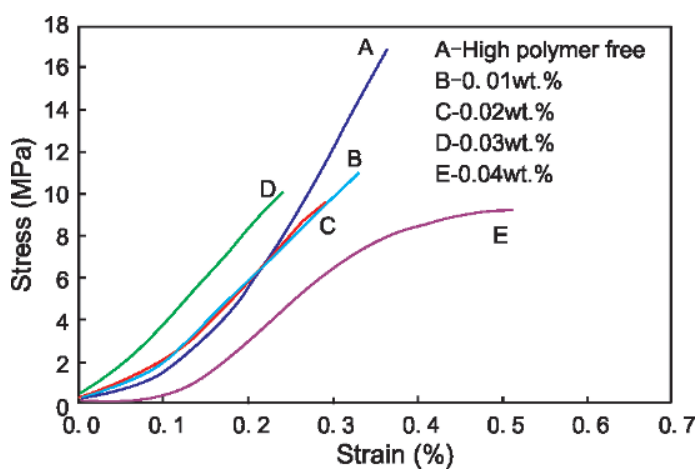

Fig. 9: Stress-strain curves of different shell molds after baking ${ }^{[18]}$

\subsection{Research progress overseas}

Norouzi et al. ${ }^{[33]}$ inspected the effect of ceramic shell mold strength on hot tearing susceptibility during solidification with the same casting conditions, but different ceramic shell mold systems. The same primary slurry was used for all shell mold systems. In the back-up layers, flours and stuccos used for the ceramic shell molds were the same, and the differences were raised exclusively by different binders and additives as shown in Table 1 .

Table 1: Different ceramic shell mold systems ${ }^{[33]}$

\begin{tabular}{ccc}
$\begin{array}{c}\text { Ceramic } \\
\text { set No. }\end{array}$ & \multicolumn{1}{c}{ Binder } & Polymer added \\
1 & Colloidal silica & - \\
2 & Colloidal silica+ ethyl silicate* & - \\
3 & Colloidal silica+ ethyl silicate* & $6 w t . \%$ polymer
\end{tabular}

* odd layers: colloidal silica; even layers: ethyl silicate

According to Table 2, polymer addition greatly decreased the fired shell mold strength due to the cavities left by the volatilized polymer. It also shows that there was a direct relationship between the ceramic strength and crack length and consequently the hot tearing susceptibility. The ceramic set No. 3 had low strength, and consequently, no hot tear was found in this group. In this case, the contraction stress during solidification can be partially released, since the external hindrance was not large enough due to the low strength of this kind of ceramic shell mold. The results showed that the lower the ceramic shell mold strength upon using polymer additives, the lower the hindered contraction rate, and the smaller the hot tearing tendency. Polymer additives reduced the fired shell mold strength and consequently reduced 
Table 2: Length of hot tearing crack corresponding to shell mold strength ${ }^{[33]}$

\begin{tabular}{cccc|}
$\begin{array}{c}\text { Ceramic } \\
\text { set No. }\end{array}$ & $\begin{array}{c}\text { Crack } \\
\text { length } \\
(\mathbf{m m})\end{array}$ & $\begin{array}{c}\text { Standard } \\
\text { deviation } \\
(\mathbf{m m})\end{array}$ & $\begin{array}{c}\text { Strength } \\
(\mathrm{MPa})\end{array}$ \\
\hline 1 & 42 & 7 & $10.3 \pm 1.5$ \\
2 & 12 & 3 & $7.1 \pm 1.1$ \\
3 & 0 & 0 & $5.6 \pm 1.3$ \\
\hline
\end{tabular}

the hot tearing probability. The ceramic shell molds fabricated by colloidal silica binder were stronger than the ceramic shell molds fabricated by a binder comprising colloidal silica and ethyl silicate. The ceramic shell mold had to be strong enough to undergo dewaxing and pouring steps; and meanwhile, weak enough to prevent hot tearing in a susceptible alloy.

Improvement of the shell molds deformability by adding fibrous materials such as glass, nylon, etc. is a conventional idea. Meanwhile, Nadolski et al. ${ }^{[34]}$ proposed a new idea of the significant replacement of silica materials with fibrous aluminosilicate materials to improve technological properties of the mold (permeability, deformation susceptibility, and thermal expansion). The examinations have been done according to the orthogonal design of the second order for four various mass fractions of the material components: ceramic fiber, silica flour, binder, and latex modifier LBS3030. The results showed that an addition of ceramic fiber to the ceramic molding material distinctly increases the permeability value of the ceramic shell mold, thus promoting gas evacuation from the mold. Simultaneously, the density of the mould decreases with an increase in the fiber quantity, which results from the skeleton structure characterized by the increased porosity. Voids in the inter-fiber spaces which caused the decrease in the bending strength can then improve the deformability of the shell mold. Another advantage of this method is that the green strength of the shell mold can also be improved due to the reinforcement effect of fiber additives, which is favorable for shell mold preparation in addition to improvement of shell mold deformability.

Recently, an investigation has been reported to improve the properties of colloidal silica based ceramic shell mold by the addition of naturally available products such as sawdust and coconut fibers into the ceramic slurries ${ }^{[35]}$. Traditional liquid

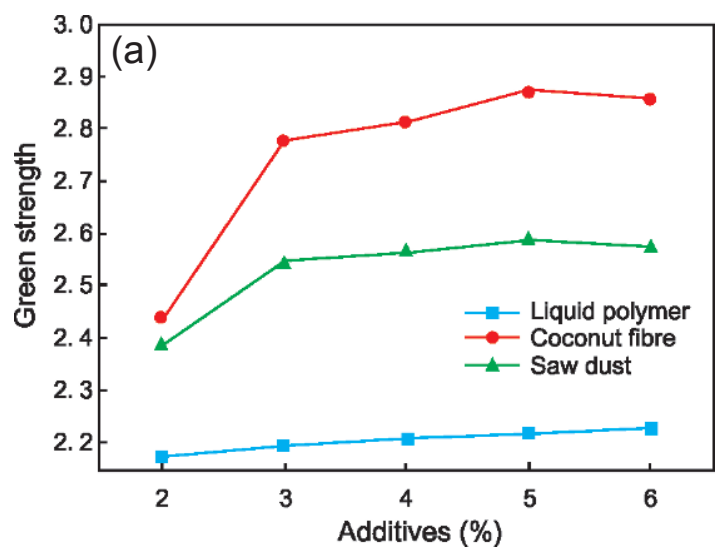

polymer, coconut fiber and sawdust were added to make P-type, C-type and S-type ceramic shell molds, respectively, as shown in Fig. 10. The strength, porosity and permeability of different shell molds, as shown in Fig. 11 and Fig. 12, indicated that different additions had different influences on ceramic properties: porosity and permeability of P-type, C-type and S-type ceramic shell molds increased with increasing percentage of additives. S-type and P-type ceramic shell molds had the highest and lowest porosity and permeability, respectively. It is seen that the median value of porosity and permeability of S-type shell mold is the highest among all shell molds and the plots are almost symmetric about the median except for the hot permeability of C-type shell mold, which is negatively skewed. Due to this higher porosity and hot permeability of the S-type shell mold, more pores are present inside it, thereby decreasing its fired strength. This means the ceramic shell mold properties can be improved by adding sawdust and coconut to the $\mathrm{SiO}_{2}$ slurry. Meanwhile, the research also found that shell mold crack may occur for different ceramic shell molds with certain additives, such as $2 \%$ liquid polymer addition in a P-type shell mold. This happened because the shell mold was very weak and thin, and least impervious, it was unable to bear the pressure of expanding wax during the dewaxing process. Porous ceramic shell mold provides space to the expanding wax thereby relieving the stress on the ceramic shell mold and thus, shell mold cracking is reduced. However, a shell mold with too much porosity also causes shell mold cracking, as it happened in the case of $6 \mathrm{wt} . \%$ additions of coconut fibers and sawdust to the ceramic slurries. Too much amount of uneven loading of additives in the ceramic matrix with

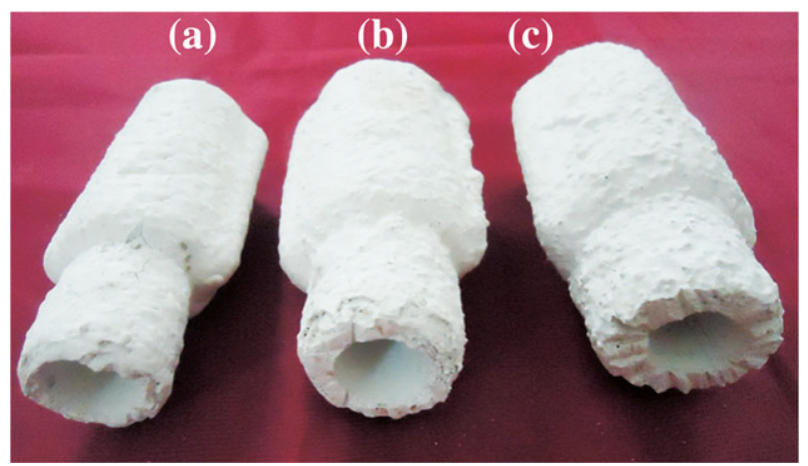

Fig. 10: Different types of ceramic shell molds: (a) P-type, (b) S-type, (c) C-type ${ }^{[35]}$

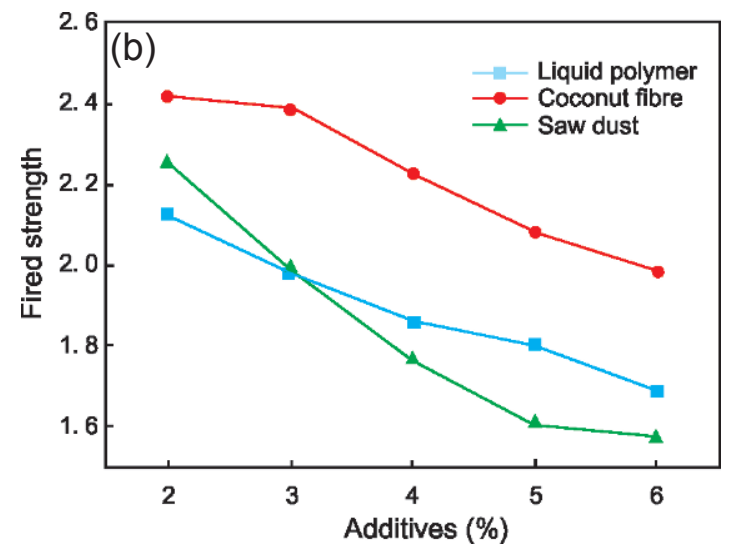

Fig. 11: Flexural strength of different ceramic shell molds at different weight percentage of additives: (a) green strength, (b) fired strength ${ }^{[35]}$ 

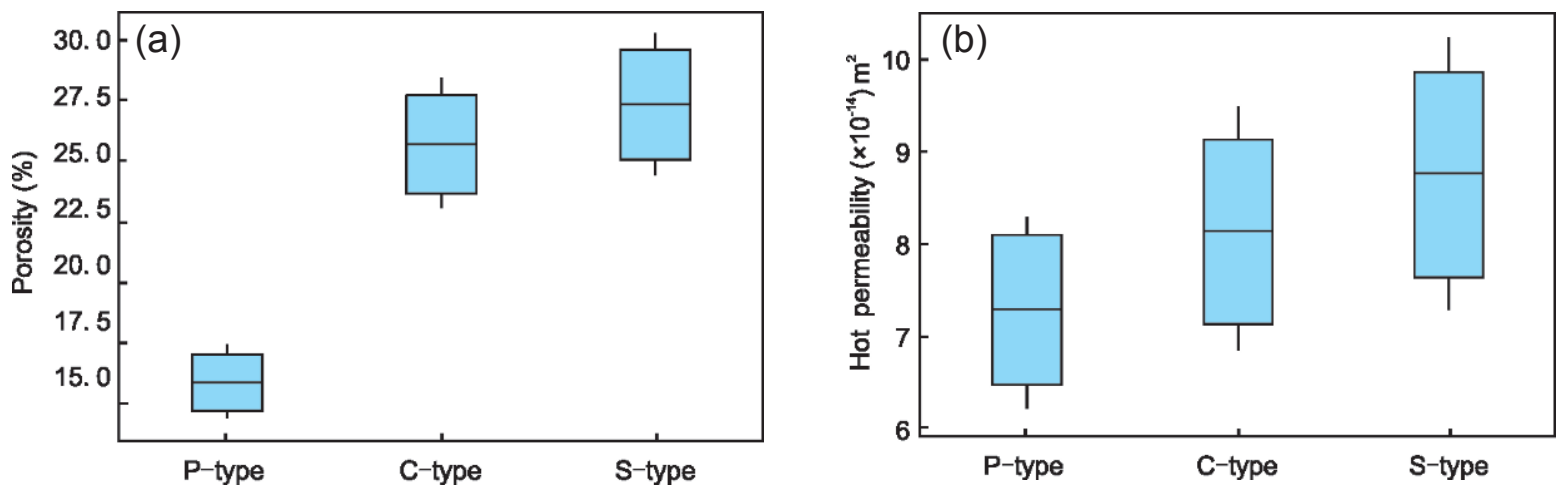

Fig. 12: Characteristics of different shell molds: (a) porosity, (b) permeability ${ }^{[35]}$

more porous structure led to shell mold cracking at $6 \mathrm{wt} . \%$ addition in the case of both C-type and S-type ceramic shell molds. So, there should be a proper percentage of additives.

Normally, bending strength, both at ambient temperature and high temperatures, is used for deformability characterization. Wedge test and I-shaped specimen methods are also proposed for improvement. However, a standard method for the deformability measurement of shell molds is still lacking.

The main method to improve shell mold deformability is to add dextrines, fibers, polymers or natural based materials into the back layers of the shell mold. The remaining porosities by additives after baking result in reduction of shell mold strength and improvement of shell mold deformability.

Change of shell mold materials is also a potential method for manufacturing a shell mold with improved strength and deformability, i.e., by using different back layer binders. The method of adding fibers in the shell mold back layers or using them alternatively with silica sol and ethyl silicate as the back layer binders have significant advantages for the increased strength before baking as well as the reduced strength after baking, which is favorable for shell mold preparation in addition to improvement of shell mold deformability.

\section{Effect of shell mold deformability on results of investment casting numerical simulation}

In order to obtain perfect quality castings, it is essential to select the appropriate casting process and technological parameters.
Considering the efficiency and cost, the traditional trial and error method is no longer suitable for the needs of modern industrial development not only because of huge cost but also the long experimental period. Numerical simulation technology shows great advantages over the conventional trial and error method on forecasting defects such as shrinkage and crack $^{[36]}$.

Many researches have been carried out for numerical simulation of TiAl alloy investment casting process for defects and dimension prediction. However, most of the studies only considered the shell mold as a rigid body which caused obvious discrepancies between simulated and experimental results especially on residual stress and crack possibility of the castings. For example, Yang et al ${ }^{[37]}$ used the numerical simulation method to study the investment casting process of high Nb-TiAl alloy for low pressure turbine blades. The thermophysical parameters of the alloy and mold material calculated by the Pandat software were applied, as shown in Table 3. Although the stress related parameters for TiAl alloy were calculated and applied for stress prediction, the ceramic shell mold was considered to be non-deformable rigid body and only heat transfer properties were taken into account for the simulation. The comparisons of predicted shrinkage and crack defects with experimental results are shown in Fig. 13 and Fig. 14, respectively. The predicted shrinkage defects had good agreement with actual blades for both castings; however, there were obvious differences on crack positions between predicted results and actual blades for both castings, which may be due to the simple supposition of a rigid shell mold.

The effects of shell mold properties on casting deformation were actually discussed as early as the 1990 s by Snow ${ }^{[38]}$

Table 3: Thermophysical parameters of TiAl alloy and mold materials ${ }^{[3]}$

\begin{tabular}{lccc} 
Ti-45Al-8Nb-1.5 $(\mathrm{Cr}, \mathrm{B}, \mathrm{Si})$ & Value & Ceramic mold & Value \\
\hline Conductivity $\left(\mathrm{W} \cdot \mathrm{m}^{-1} \cdot \mathrm{K}^{-1}\right)$ & $15-26$ & Conductivity $\left(\mathrm{W} \cdot \mathrm{m}^{-1} \cdot \mathrm{K}^{-1}\right)$ & $0.83-0.97$ \\
Density $\left(\mathrm{kg} \cdot \mathrm{m}^{-3}\right)$ & $4,135-4,513$ & Density $\left(\mathrm{kg} \cdot \mathrm{m}^{-3}\right)$ & 2,780 \\
Specific heat $\left(\mathrm{kJ} \cdot \mathrm{kg}^{-1} \cdot \mathrm{K}^{-1}\right)$ & $0.63-1.02$ & Specific heat $\left(\mathrm{kJ} \cdot \mathrm{kg}^{-1} \cdot \mathrm{K}^{-1}\right)$ & $0.44-0.85$ \\
Enthalpy $\left(\mathrm{kJ} \cdot \mathrm{kg}^{-1}\right)$ & 330 & & \\
Liquidus temperature $\left({ }^{\circ} \mathrm{C}\right)$ & 1,578 & \\
Solidus temperature $\left({ }^{\circ} \mathrm{C}\right)$ & 1,405 & \\
Viscosity $(\mathrm{Pa} \cdot \mathrm{s})$ & $(4.65-8.8) \times 10^{-3}$ &
\end{tabular}


and Piwonka ${ }^{[39]}$, and their research results indicated that the deformation of the mold must be considered in order to predict the final dimensions of the investment casting parts. However, for a long time, while the study of casting quality using
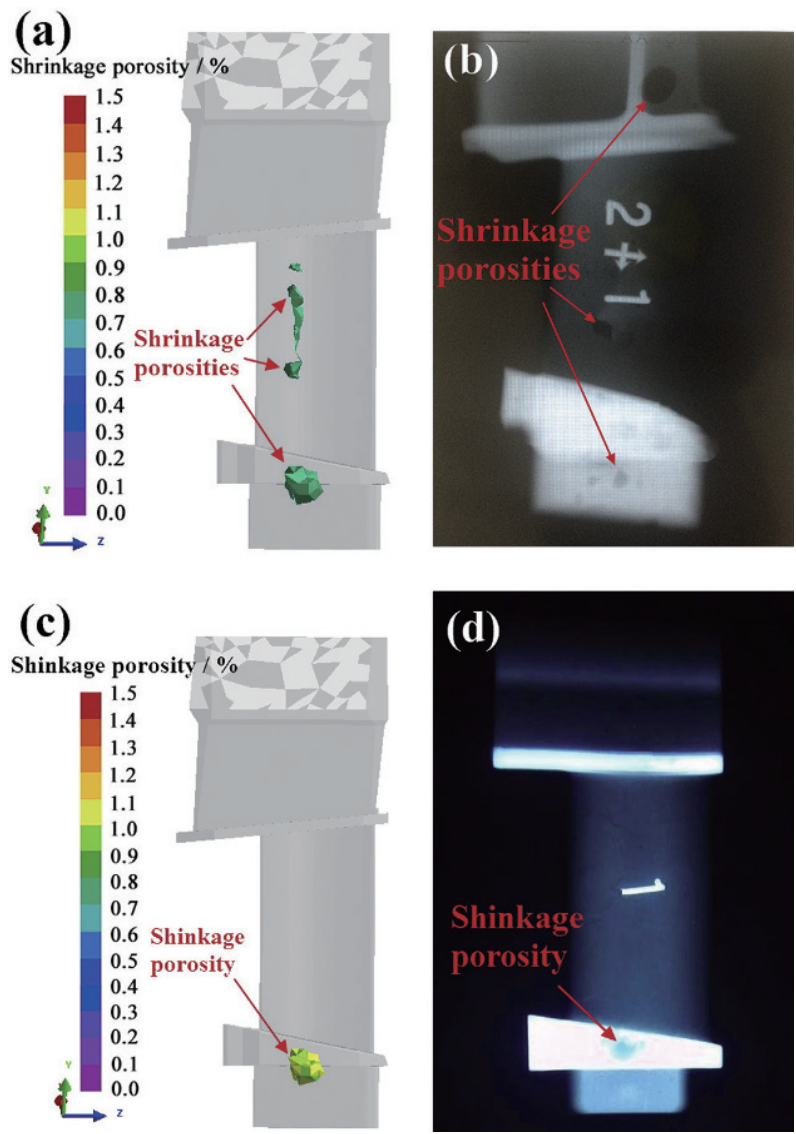

Fig. 13: Positional distribution of shrinkage porosities: (a) and (c) simulation results; (b) and (d) X-ray/ fluorescence detection of actual blades ${ }^{[37]}$

Only very recently trials were made to consider the shell mold as a deformable body during casting process simulation. For example, Adrian $\mathrm{S} \mathrm{S}^{[40]}$ predicted the dimensions of investment castings by changing the property of molds. Case studies were carried out for parts with no hole and two holes, as both rigid and elastic models were selected for the shell mold. The Young's modulus of 2,586 MPa provided by Minco, Inc. was used for numerical simulation when the shell mold was considered a numerical method became popular, the effect of shell mold deformation was not fully considered as the shell mold was only set to be a rigid part (a)

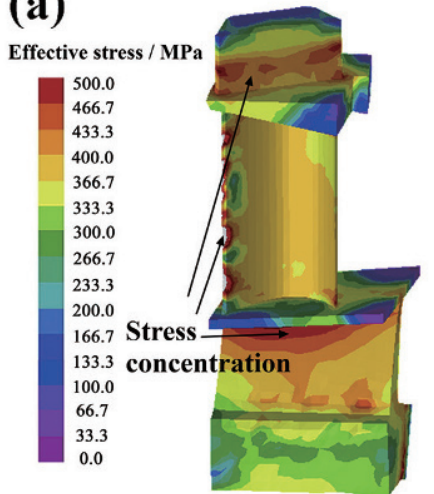

(c)

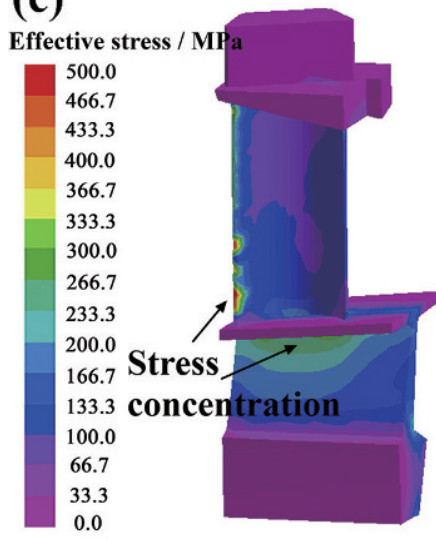

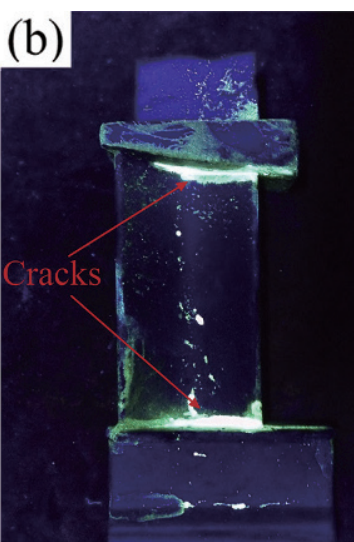

(d)

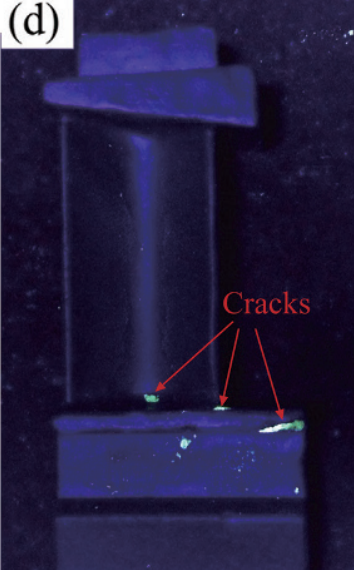

Fig. 14: Stress concentration and cracks: (a) and (b) gravity casting; (c) and (d) centrifugal casting ${ }^{[37]}$

linear-elastic deformable material. The comparison of the results of the experimental and numerical simulations, as shown in Table 4, indicates that the best results were obtained for the case in which an elastic mold and $f_{p k}=90$ pct were considered $\left(f_{p k}\right.$ $=90$ pct was considered the point at which the stress calculations started in ProCAST). The final results showed that accurate predictions were obtained for all measured dimensions when the shell mold was considered as a deformable material.

Table 4: Summary of numerical simulation results (- under predicted, +over predicted, $X$ good agreement) ${ }^{[40]}$

\begin{tabular}{|c|c|c|c|c|c|c|c|}
\hline \multirow{2}{*}{ Cases } & \multirow{2}{*}{$f_{p k}(p c t)$} & \multirow{2}{*}{ Mold type } & \multicolumn{3}{|c|}{ Unrestrained dimensions } & \multirow{2}{*}{$\begin{array}{l}\text { Restrained dimensions } \\
\text { Representative length } \\
\text { (two holes) }\end{array}$} & \multirow{2}{*}{ Agreement } \\
\hline & & & $\begin{array}{l}\text { Representative } \\
\text { length (no holes) }\end{array}$ & Width (no holes) & Width (two holes) & & \\
\hline 2 & 90 & rigid & $x$ & $x$ & $x$ & - & \\
\hline 3 & 70 & rigid & + & + & + & - & \\
\hline 4 & 90 & elastic & $x$ & $x$ & $x$ & $x$ & $x$ \\
\hline 5 & 70 & elastic & + & + & + & $x$ & \\
\hline
\end{tabular}


In 2016, Wang et al. ${ }^{[41]}$ adopted a coupled thermomechanical analysis method for dimensional shrinkage prediction during the investment casting process by setting both the casting and the mold deformable bodies in a contact boundary model. Although the detailed deformable parameters for the mold were not given, the perfect agreement between numerical results and practical productions showed that the method was effective and could improve dimensional accuracy and consistency in investment casting.

From the above review of numerical study of investment casting with different considerations of mold properties, it can be found that a deformable setting for the shell mold is crucial for accurate prediction of stress and dimension related defects. So, the characterization of deformability and proper modeling of the deformability for a shell mold is very important for the further development of investment casting process of TiAl alloys.

\section{Proposal for future study of deformability of TiAl casting shell mold}

With a more and more wide application of TiAl alloy investment castings, increasing casting quality and reducing cost become important considerations. Reduction of defects including cracks through the improvement of shell mold deformability can be an efficient method. However, the present study on shell mold deformability cannot meet the demand of practical application, and further research is needed in the following aspects:

(1) Methods for shell mold deformability assessment

The operation of frequently used I-shaped specimen method for deformability assessment is complex and the results strongly depend on the geometry of specimens. The compressive strength and bending strength are normally only usable for room temperature testing of the shell mold and the measured deformability shows a great difference compared to high temperature which is the real service condition of shell molds. So, proposing a simple quantitative assessment method for real deformability of shell molds under service condition is the base of a systematic deformability study in the future.

(2) Numerical prediction of the effect of shell mold deformability during investment casting process

With the development of computers and numerical methods, numerical simulation of the casting process can be an efficient tool for designing the shell mold. Present available research already indicates that considering the shell mold as a deformable body in the numerical models is important to accurately predict results. However, only linear elastic materials were considered in present studies for deformable shell mold for simplification, while the experiment of stress-strain curves for ceramic shell mold indicated more complicated deformation behavior ${ }^{[3]}$. So, introduction of a certain deformability index or proper materials deformation model for shell mold in numerical models to simulate the influence of shell mold deformability on casting quality and obtain an optimized shell mold design will be a main development trend for shell molds in the future.

(3) Methods for shell mold deformability improvement

The present method for the reduction of deformability by some additions to form cavities after shell mold baking has a certain effect, but is only applicable for certain simple castings because systematic study is still lacking. So, systematic and quantitative study for deformability improvement methods can achieve universal results to guide the design and manufacturing of shell molds for large and complex TiAl alloy castings.

\section{Summary}

Based on a review of the research progress on the deformability of shell molds for TiAl alloy castings and numerical simulation advancement for a TiAl alloy precision casting process, the following conclusions can be reached:

(1) A standard method for deformability measurement of shell molds is still lacking. At present, bending strength both at ambient temperature and high temperatures are frequently used for deformability characterization. Wedge test and I-shaped specimen methods are also proposed and applied recently.

(2) The main method to improve shell mold deformability is to change the composition of the shell mold, and two ways were reported: by adding dextrines, fibers, polymers or natural based materials into the back layers of the shell mold, and by using different back layer binders. For the first way, the remaining porosities by additives after baking result in reduction of shell mold strength; and for the second way, reduction of binding strength between slurry and sands can be realized by reducing the viscosity of the slurry. For both ways, the increased strength before baking as well as the reduced strength after baking, are favorable for shell mold preparation in addition to improvement of shell mold deformability. However, the present methods for deformability improvement were only applicable for certain simple castings. Systematic and quantitative studies for deformability improvement methods are still needed to obtain universal results and guide the design and manufacturing of shell molds for large and complex TiAl alloy castings.

(3) Considering the shell mold as a deformable body in the numerical models is important for the predicted result accuracy for stress and dimension related defects. However, only linear elastic materials were considered in present studies for deformable shell mold for simplification. Introduction of a certain deformability index or proper materials deformation models for a shell mold in numerical models will be a main development trend for shell molds in the future.

\section{References}

[1] Loria E A. Gamma titanium aluminides as prospective structural materials. Intermetallics, 2000, 8(9-11): 1339-1345.

[2] Wu X. Review of alloy and process development of TiAl alloys. Intermetallics, 2006, 14(10-11): 1114-1122.

[3] Peng Chaoqun, Huang Baiyun, He Yuehui. Relationships among technologies, microstructures and mechanical properties of TiAl-based alloys. The Chinese Journal of Nonferrous Metals. 
2001,11(04): 527-540. (In Chinese)

[4] Gao Lijie. Calculation of mechanical properties and theory mechanisms of TiAl intermetallic compounds. Dissertation: Hunan University, 2010: 1-68. (In Chinese)

[5] Chen Yuyong, Su Yongjun, Kong Fantao. Research progress in preparation of TiAl interemetallic based compound. Rare Metal Material and Engineering, 2014, 43(03): 757-762. (In Chinese)

[6] Lin Junpin, Zhang Laiqi, Song Xiping, et al. Status of research and development of Light-Weight $\gamma$-TiAl intermetallic based compounds. Materials China, 2010, 29(02): 1-8. (In Chinese)

[7] Gong Yansheng. Investigation on the synthesis and performance of TiC particulates reinforced TiAl intermetallic matrix composites. Dissertation: Jinan University, 2003: 1-39. (In Chinese)

[8] Kim M G, Sung S Y, Kim Y J. Microstructure, metal-mold reaction and fluidity of investment cast-TiAl alloys. Materials Transactions, 2004, 45(2): 536-541.

[9] Wang Shouren, Guo Peiquan, Yang Liying. Centrifugal precision cast TiAl turbocharger wheel using ceramic mold. Journal of Materials Processing Technology, 2008, 1-3: 492-497.

[10] Su Yanqing, Guo Jingjie, JiaJun, et al. Centrifugal investment casting of a TiAl-Based turbine blade. Rare Metal Materials and Engineering, 2002, 4: 295-298. (In Chinese)

[11] Wang Yu. Study on investment casting stress and defect of Ti48Al-2Cr-2Nb. Dissertation: Harbin Institute of Technology, 2013:1-79. (In Chinese)

[12] Wan Yuanbin. Study on investment casting defects of TiAl alloys. Dissertation: Harbin Institute of Technology, 2009: 1-75. (In Chinese)

[13] Leyland S P, Hyde R, Withey P A. The fitness for purpose of investment casting shells. In: Proceedings of 8th International Symposium on Investment Casting (Precast 95), Brno, Czech Republic, 1995: 62-68.

[14] Wan Y B. Study on investment casting defects of TiAl alloy. Dissertation, Harbin Institute of Technology, 2009: 1-64. (In Chinese)

[15] Jia Q, Cui $Y$ Y, Yang R. A study of two refractories as mould materials for investment casting TiAl based alloys. Journal of Materials Science, 2006, 41 (10): 3045-3049.

[16] Zhou Hao. Research on deformability of shell for precision casting thin-wall TiAl alloy castings. China Foundry, 2013, 62(08): 781783. (In Chinese)

[17] lasalle. Inert Calcia Facecoats for Investment Casting of Titanium and Titanium Aluminide Alloys. US patent no.: 5766329, 1998.

[18] Chen Yanfei, Xiao Shulong, Tian Jing, et al. Improvement in collapsibility of $\mathrm{ZrO} 2$ ceramic mould for investment casting of TiAl alloys. China Foundry, 2011, 1: 9-13.

[19] Wang Kuangfei, Li Changyun, Cui Hongbao. Numerical simulation of Titanium alloy forming process. Metallurgy Industry Press, 2009. (In Chinese)

[20] Zhao Song. Research on investment casting of Ti-47Al-2Cr-2Nb of alloys. Dissertation, Harbin Institute of Technology, 2008: 1-63. (In Chinese)

[21] Chen Yuyong, Chen Yanfei, Tian Jing, et al. Development and research status of investment casting TiAl-Based alloys. Rare Metal Material and Engineering, 2009, 38(03): 554-558. (In Chinese)

[22] Huang Dong, Xie Chengmu, Nan Hai, et al. Foreign study on rrefractirues for investment casting. Spceial casting and Nonferrous alloys, 2004 (03): 46-49. (In Chinese)

[23] Kim S K, Kim T K, Kim M G, et al. Investment casting of titanium alloys with $\mathrm{CaO}$ crucible and $\mathrm{CaZrO}_{3}$ mold. Lightweight Alloys for Aerospace Application, John Wiley \& Sons, Inc. 2001: 251-260.
[24] Li C H, Gao Y H, Xiong W Z D, et al. Interaction between the ceramic $\mathrm{CaZrO}_{3}$ and the melt of titanium alloys. Adv. Sci. Technol., 70 (2010): 136-140.

[25] Li C H, Zhou F F, Lu X G, et al. $\mathrm{CaZrO}_{3}$ mold shell used for titanium and titanium alloy precision casting and preparation method, China Patent No. 103071764 A.

[26] Kuang J P, Harding R A and Campbell J. Investigation into refractories as crucible and mould materials for melting and casting $\mathrm{Y}$-TiAl alloys. Materials Science Technology, 2000,16 (9): 1007-1016.

[27] Wang J F, Wang J N and Yang J. Interface reaction of TiA1 based alloy with some ceramic materials. Special Casting \& Nonferrous Alloys, 2002 (5): 40-42. (In Chinese)

[28] Kim M G, Kim Y J. Investigation of interface reaction between TiAl alloys and mold materials. Metals and Materials International, 2002, 8(3): 289-293.

[29] Song Xiangjun, Luojirong. The evaluate method and improve measure of high temperature formability of nobake furan resin sand bonded mold. Hot Working Technology, 2001, 2(25): 56-57. (In Chinese)

[30] Chen Yanfei, Xiao Shulong, Tian Jing, et al. Effect of particle size distribution on properties of zirconia ceramic mould for TiAl investment casting. Transactions of Nonferrous Metals Society of China, 2011, 21: 342-347.

[31] Li Baohui, Hou Zhengquan, Qiu Lixin, et al. Development of research on precision forming of TiAl alloys. Aerospace Materials and Technology, 2008, 05: 4-7. (In Chinese)

[32] Sun Minjie, Chen Yuyong, Li Baohui, et al. Technology research on the oxide ceramic mould for investment casting of TiAl-based alloys. Aerospace Manufacturing Technology, 2012, 05: 45-48. (In Chinese)

[33] Saeid Norouzi and Hassan Farhangi. The impact of ceramic shell strength on hot tearing during investment casting. In: AIP Conference Proceedings: International conference on advances in material and processing technologies (AMPT 2010), American Institute of Physics, 2011, 1315: 662-667.

[34] Nadolski M J, Konopka Z. The investigation of properties of investment casting moulds reinforced with ceramic fibre. Archives of Foundry Engineering, 2007, 7(4): 127-130.

[35] Sarojrani Pattnaik1. An investigation on enhancing ceramic shell properties using naturally available additives. International Journal of Advanced Manufacture Technology, 2017: 1-18.

[36] Gebelin J C, Jolly M R. Modeling of the investment casting process. Journal of Material Processing Technology, 2003, 135: 291-300.

[37] Yang L, Chai L H, Liang Y F, et al. Numerical simulation and experimental verification of gravity and centrifugal investment casting low pressure turbine blades for high Nb-TiAl alloy. Intermetallics, 2015, 66: 149-155.

[38] Snow J D. What happens during Autoclave dewaxing. In: Proc. 46rd Annual Meeting of the Investment Casting Institute, Orlando, 1998.

[39] Piwonka T S. Factors affecting investment casting pattern die dimensions. In: Proc. 8th World Conf. on Investment Casting, London, 1993.

[40] Adrian S S. Alloy shrinkage factors for the investment casting process. Metallurgical and Material Transactions B, 2006, 37: 131-140.

[41] Wang Donghong, He Bo, Liu Shumei, et al. Dimensional shrinkage prediction based on displacement field in investment casting. International Journal of Advanced Manufacture Technology, 2016, 85: 201-208. 